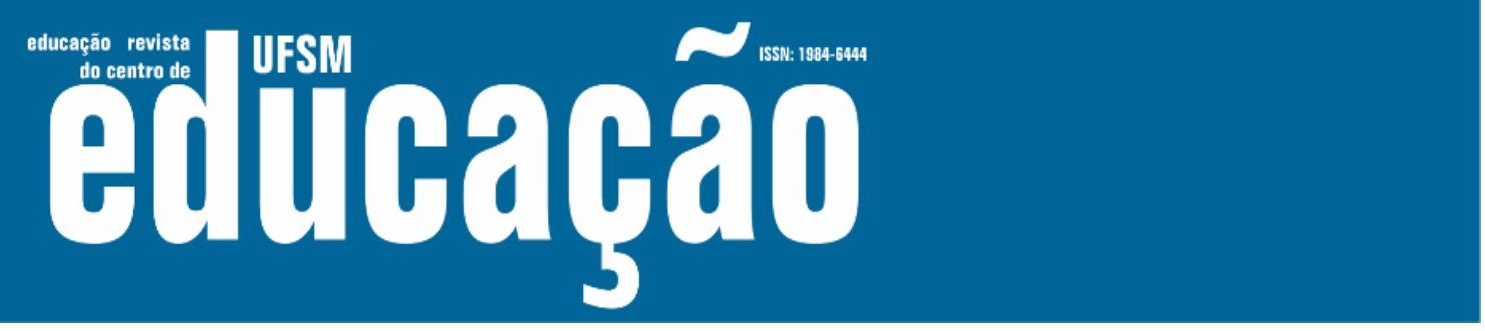

ISSN: 1984-6444 | http://dx.doi.org/10.5902/1984644431227

\title{
O ensino de Relações Públicas em frente à cultura digital no Brasil, Argentina e Uruguai
}

\author{
Public Relations education facing digital culture in Brazil, Argentina, and \\ Uruguay
}

\author{
Valmor Rhoden \\ Professor adjunto na Universidade Federal do Pampa, São Borja, Rio Grande do Sul, Brasil. \\ vrhoden6@gmail.com - http://orcid.org/0000-0001-6014-1057
}

\section{Valeska Maria Fortes de Oliveira}

Professora doutora na Universidade Federal de Santa Maria, Santa Maria, Rio Grande do Sul, Brasil. vfortesdeoliveira@gmail.com - https://orcid.org/0000-0002-8295-1007

Recebido em 20 de fevereiro de 2018

Aprovado em 11 de setembro de 2018

Publicado em 17 de dezembro de 2019

\section{RESUMO}

Esta pesquisa teve como objetivo comparar as Diretrizes Curriculares Nacionais de Relações Públicas de Brasil, Argentina e Uruguai e refletir a respeito da formação recebida pelos universitários da área. A metodologia conta com pesquisa bibliográfica e amparo documental. O ensino superior representa a preparação cidadã e profissional para o mundo do trabalho e, neste artigo, compara-se a realidade brasileira com a dos países vizinhos no que tange o ensino de Relações Públicas no âmbito digital. Os resultados mostraram que, apenas no Brasil, há diretrizes curriculares especificadas em âmbito nacional, criadas em 2013. A respeito da carga horária, há diferença significativa entre os países estudados. $E$ em relação ao presente cenário, que insere a profissão de Relações Públicas na cultura digital, percebemos que tal mudança é discutida de forma incipiente pela documentação oficial brasileira. Ademais, outro ponto observado é que, na Argentina e no Uruguai, os cursos de Relações Públicas têm autonomia para criar seus conteúdos.

Palavras-chave: Ensino superior; Relações Públicas; Cultura Digital.

\section{ABSTRACT}

This paper aimed to compare the National Curriculum Guidelines for Public Relations between Brazil, Argentina and Uruguay, and reflect on the training received by university students in that area. The methodology relies on bibliographic research and documentary support. Higher education represents the preparation of the professional for the world of work and in this article, the Brazilian reality is compared with that of neighboring countries in what concerns the teaching of Public Relations in the digital 


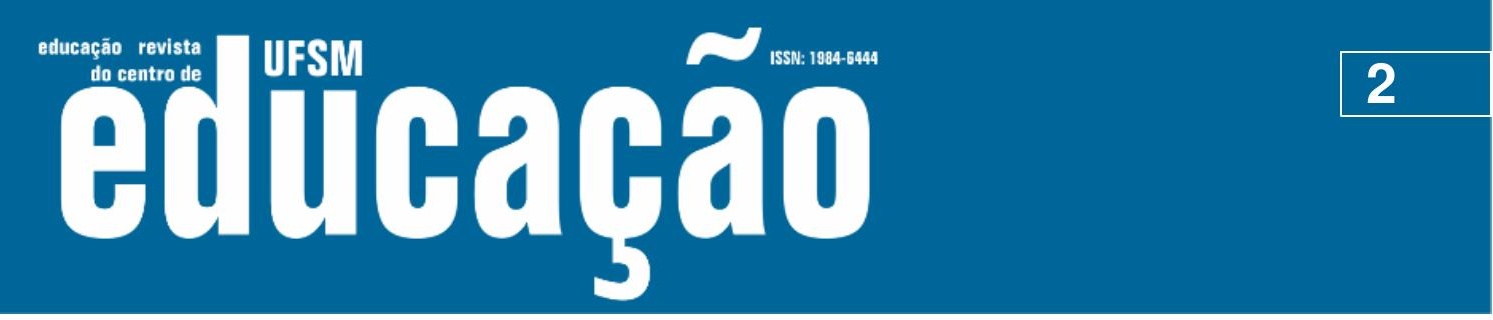

ISSN: 1984-6444 | http://dx.doi.org/10.5902/1984644431227

scope. Higher education represents the preparation of the professional for the world of work and in this article, the Brazilian reality is compared with that of neighboring countries in what concerns the teaching of Public Relations in the digital scope. Results showed that only in Brazil there are nationally specified guidelines, created in 2013. Regarding the workload, there is a significant difference between the countries under analysis. And concerning the current scenario, which inserts the profession of Public Relations in the digital culture, we realize that such a change is incipiently discussed by the official Brazilian documentation. Also, another point observed is that, in Argentina and Uruguay, Public Relations courses have the autonomy to create their own content.

Keywords: Higher education; Public relations; Digital culture.

\title{
Introdução
}

Uma das principais práticas que transformam o mundo do trabalho é a comunicação. Barichello descreveu a implicação desse cenário nas organizações e, consequentemente, entre os gestores comunicacionais, ressaltando a interatividade com os públicos e a convergência propiciada pelo ambiente digital:

\begin{abstract}
As organizações contemporâneas precisam fazer mais do que utilizar estratégias de comunicação mediadas pelo computador. Elas necessitam, sobretudo, assimilar esses novos patamares espaciotemporais nas suas atividades cotidianas. É preciso utilizar, especialmente, duas propriedades estruturais da comunicação digital: a potencialização da interatividade com os públicos e a convergência de ações possíveis em um mesmo dispositivo de comunicação (BARRICHELLO, 2009, p. 351).
\end{abstract}

Tais desafios estão postos para a área de Relações Públicas ${ }^{1}$ enquanto profissão e também se colocam como uma preocupação relacionada à formação acadêmica dos novos profissionais - questão que surge ao refletirmos sobre a relação da teoria e da prática como esferas balizadoras das propostas curriculares.

Estima-se que cerca de 3,2 bilhões de pessoas (número correspondente a cerca de $40 \%$ da população mundial) tem acesso à internet, de acordo com a UIT (União Internacional de Telecomunicações) e divulgado pelo portal G1 (2015) ${ }^{2}$. Desse modo, o cenário global transforma-se em meio à crescente cultura digital, que estabelece novos modos de ser, pensar e agir com respaldo das possibilidades oferecidas pelas tecnologias digitais de informação e comunicação. Porém, estariam os cursos universitários de Relações Públicas atentos a tais mudanças? E no Brasil, 


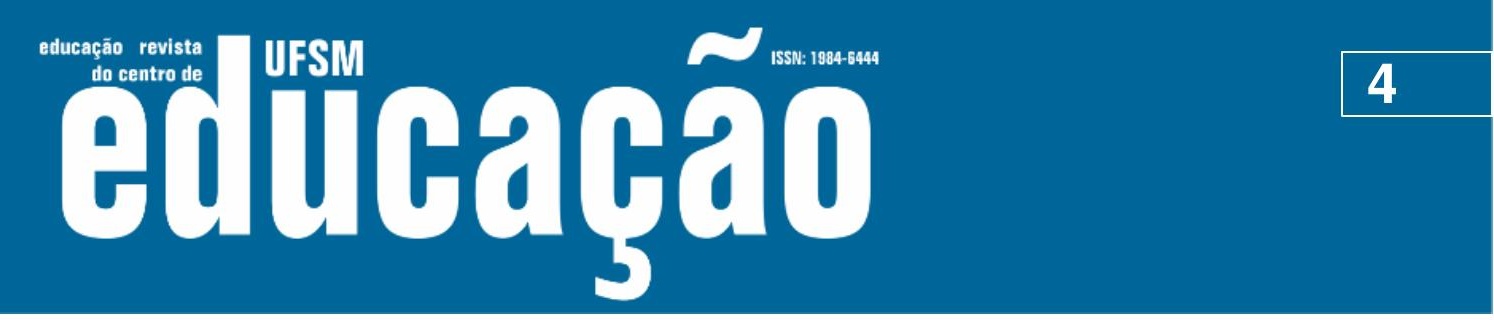

ISSN: 1984-6444 | http://dx.doi.org/10.5902/1984644431227

A fim de cumprir a proposta de estudo, além da revisão bibliográfica, a principal ferramenta utilizada para a condução do trabalho é a análise documental, compreendendo registros que servem de fonte relevante sobre a temática. Para a construção do texto, foram pesquisadas referências específicas da área, especialmente as seguintes: Resolução $n^{\circ} 2$, de 27 de setembro de 2013 do Brasil; Resolução nำ6, de 13 de fevereiro de 1997, da Argentina; Decreto nํ104/14, de 24 de abril de 2014, do Uruguai.

E em vista do caráter que sugerimos para este estudo, trazemos a noção de comparação em educação como uma história de significados (CUNHA; ISAIA, 2006), ou seja, os sentidos que as diferentes comunidades dão às suas ações e que lhes permitem construir e reconstruir o mundo. Nesse sentido, o artigo apresenta a realidade das diretrizes da área de Relações Públicas dos três países supramencionados, que serão analisados e, após, comparados em linhas gerais. Trata-se de uma tentativa que não reivindica a explicação singular, mas que se reconheça na complexidade das significações, abrangendo os limites de sua interpretação. Nesse sentido, compreende-se que as diretrizes influenciam no ensino superior através de linhas mínimas de formação e que há vários outros fatores condicionantes que envolvem as instituições de ensino, a gestão dos cursos e os corpos docentes, o que torna possível uma instrução atualizada na área.

\section{A formação de Relações Públicas nos países estudados na era da cultural digital}

A cultura digital desenvolveu-se mais, no sentido da comunicação e da sociabilidade, por meio do avanço tecnológico. Os usuários assumiram os postos de produtores de conteúdos, apresentando-se como autores e atores sociais participantes de ilimitadas redes de conexões, pelas quais as informações trafegam sem fronteiras. Esta é uma realidade da cultura digital, somos emissores de informação ao mesmo tempo em que também ocupamos o papel de receptores. Nesse sentido, como reforça Bauman (1999, p. 84), "estamos todos em movimento". No contexto atual, isso se dá por meio de uma dinâmica em que nos conectamos, 


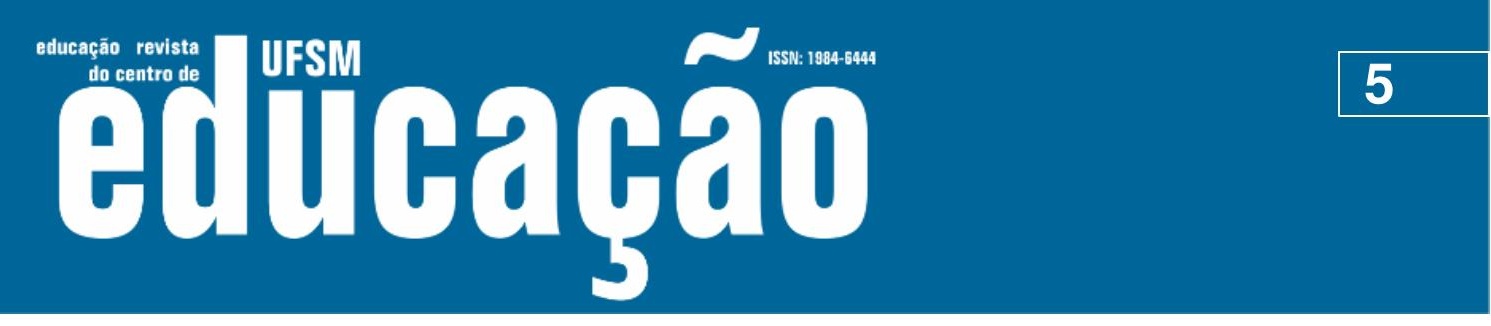

ISSN: 1984-6444 | http://dx.doi.org/10.5902/1984644431227

através da internet, 24 horas por dia. Em dossiê publicado pela revista Telos, Castells define a cultura digital em seis tópicos:

\begin{abstract}
1. Habilidade para comunicar ou mesclar qualquer produto baseado em uma linguagem comum digital; 2. Habilidade para comunicar desde o local até 0 global em tempo real e, vice-versa, para poder aumentar o processo de interação; 3. Existência de múltiplas modalidades de comunicação; 4. Interconexão de todas as redes digitalizadas de bases de dados ou a realização do sonho do hipertexto de Nelson com o sistema de armazenamento e recuperação de dados, batizado como Xanadú, em 1965; 5. Capacidade de reconfigurar todas as configurações criando um novo sentido nas diferentes camadas dos processos de comunicação; 6 . Constituição gradual da mente coletiva pelo trabalho em rede, mediante um conjunto de cérebros sem limite algum. Neste ponto, me refiro às conexões entre cérebros em rede e a mente coletiva. (CASTELLS, 2008, p. 03).
\end{abstract}

Ainda segundo o autor, a cultura da internet é "uma crença tecnocrática no progresso dos seres humanos através da tecnologia" (CASTELLS, 2003, p. 53). Nesta pesquisa, a cultura digital é entendida sob a mesma perspectiva defendida por Bortolazzo :

[...] compreende-se que um conjunto de elementos atrelados ao digital, incluindo os sites pessoais ou institucionais, as redes sociais, os artefatos digitais, entre muitos outros, e todos os tipos de relações que os sujeitos mantêm, compõem parte de um emaranhado de conceitos e ideias que ajudam a produzir a Cultura Digital. (BORTOLAZZO, 2016, p. 13).

Desse modo, emerge um desafio para o ensino superior, ou seja, a questão não é somente ensinar a tecnologia e obter métricas: é preciso saber o que fazer com todos os dados que circulam. Como reforça Maciel (2009, p. 283), "a mera reprodução de teorias e métodos não prepara o profissional para acompanhar a mutabilidade do mundo e da realidade de sua profissão".

No âmbito da educação de nível superior no Brasil, com relação à área de Relações Públicas, as DCNs são parâmetros elaborados pelo Ministério da Educação para orientar a formação. Segundo a Resolução nํㅜ 2, de 27 de setembro de 2013:

Art. $2^{\circ}$ A organização de cursos de graduação em Relações Públicas, resguardadas as Diretrizes Curriculares Nacionais e os Pareceres desta Câmara, deverá ser elaborada com claro estabelecimento de componentes curriculares, os quais, sem prejuízo de outros aspectos, abrangerão: I projeto pedagógico e matriz curricular; II - linhas de formação; III - articulação teórico-prática; IV - processos de atualização; V - carga horária total; VI estrutura laboratorial; VII - descrição de competências gerais e específicas; VIII - habilidades e perfil desejado para o futuro profissional; IX - conteúdos curriculares; X - estágio curricular supervisionado; XI - acompanhamento e 


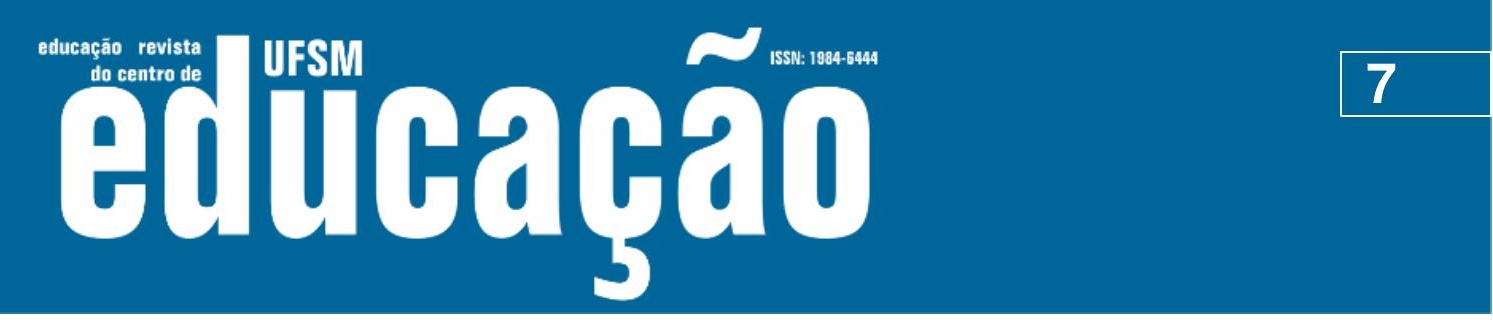

ISSN: 1984-6444 | http://dx.doi.org/10.5902/1984644431227

No debate sobre inovação na educação superior é possível afirmar que:

La gran acumulación de conocimiento, su rápida obsolencia y la renovación y nacimiento de nuevos cuerpos de contenidos marcan la necesidad de pensar en otras formas de organizar los contenidos programáticos y de diseñar nuevas estrategias de enseñanza-aprendizaje $(E-A)$ y de evaluación de dichos aprendizajes. (CARRASCO, 2013, p. 49).

A forma como vem sendo concebida e organizada a discussão curricular, no contexto da educação superior, obstaculiza pensar em propostas de trabalho e mediação pedagógica capazes de responder a diferentes demandas da sociedade do conhecimento e do mundo do trabalho, que precisam ser problematizadas e enfrentadas no espaço da universidade. As representações dos professores universitários, formados numa lógica da especialização e monodisciplinar, têm criado dificuldades para o exercício imaginativo de outros desenhos curriculares.

\begin{abstract}
Esta concepção produz ainda, dificuldades de ações e propostas de trabalhos interdisciplinares em que as temáticas seriam agregadoras de abordagens mais complexas e menos redutoras (reducionistas) como aponta Morin (1994, 2001). A lógica monodisciplinar dos nossos currículos de formação de professores acabou por configurar uma professoralidade especializada e isolada. (OLIVEIRA, 2003, p. 254).
\end{abstract}

Essa concepção, em outras áreas que não a formação de professores, configura-se como uma profissionalização especializada, não permitindo ao estudante, no espaço da universidade, a religação de saberes, que, no mundo do trabalho e da vida, apresentam-se inter-relacionados. Ainda, o isolamento de algumas propostas curriculares da esfera profissional e das demandas da sociedade atual produz, no aluno, ao se inserir no seu campo de atuação, a sensação de que foi preparado para desafios que já são outros.

Agora, em um momento de constantes mudanças, em razão da expansão da cultura digital, o contexto do ensino superior de Relações Públicas na cultura digital encontra-se em meio à complexidade, não podendo ser estudado de forma genérica, o que implicaria o risco de encobrir perspectivas específicas.

O avanço da internet e a expansão dos meios de comunicação digitais criaram descompasso entre o mundo do trabalho e os cursos que preparam os futuros profissionais de Relações Públicas. O ritmo acelerado do desenvolvimento 


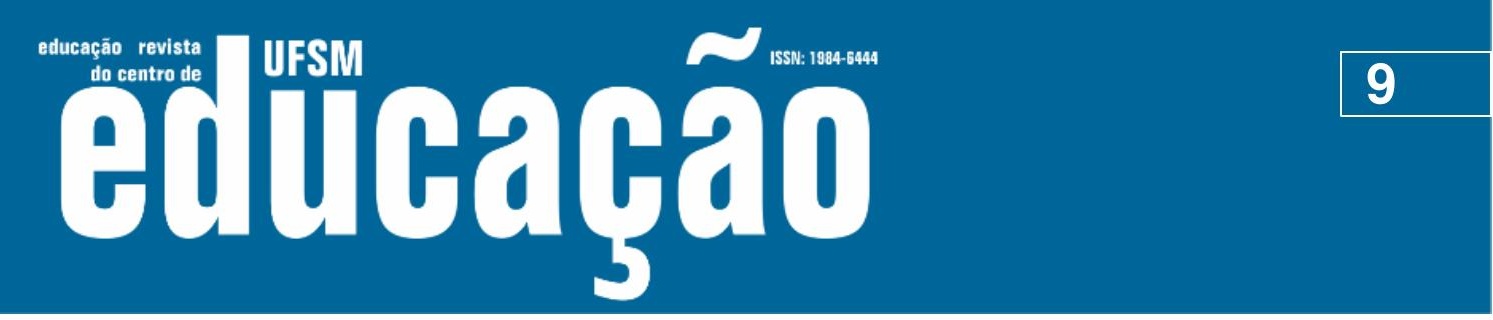

ISSN: 1984-6444 | http://dx.doi.org/10.5902/1984644431227

\section{A trajetória do ensino superior de Relações Públicas no Brasil}

Considerando-se como marco histórico a criação do curso de Jornalismo pela Universidade do Distrito Federal, em 1947, o ensino de comunicação, no Brasil, tem 70 anos. A formação na área começou vinculada ao Jornalismo, devido a seus precursores, em sua maioria, terem sido, originariamente, integrantes da imprensa, mas havia uma referência às Relações Públicas (MOURA, 2002).

Já o primeiro curso superior de Relações Públicas, com duração de quatro anos, foi criado 20 anos depois, em 1967, com a fundação da Escola de Comunicações Culturais, na Universidade de São Paulo, conhecida, atualmente, como Escola de Comunicação e Artes (TEIXEIRA, 2002). Nesse período foi sancionada a Lei $n^{\circ} .5 .377$ (BRASIL, 1967) disciplinando a profissão e tornando o Brasil o primeiro país do mundo a adotar uma legislação específica para a área de Relações Públicas. Esse fato desencadeou a criação de várias faculdades e departamentos em âmbito nacional.

De acordo com Campanella (2008 p. 68-9), “[...] o número de faculdades de comunicação, no Brasil, em 1974 - nem todas possuindo o Curso de Relações Públicas - era de 54, sendo 15 em São Paulo, dez, no Rio de Janeiro e as demais nos outros estados". A qualidade de ensino ministrada era problemática, segundo apontado por Marques de Melo (2007), com programas desatualizados e distantes da realidade brasileira.

Em 1984 formulou-se um novo currículo mínimo com a Resolução $n^{\circ} 2 / 84$, que trouxe exigências de infraestrutura para instalações, laboratórios e equipamentos adequados à formação profissional nas diferentes áreas da comunicação, além dos projetos experimentais obrigatórios nos cursos de Relações Públicas. O processo de redemocratização do Brasil, que desencadeou as eleições diretas em 1984, foi um aspecto que auxiliou para que a profissão deixasse o viés apenas governamental, muito atrelado a cerimonial e protocolo durante o período dos governos militares, e começasse a se inserir no âmbito organizacional (MOURA, 2002).

A década de 1990 denotou um marco especialmente importante, devido ao desenvolvimento da internet e ao surgimento das tecnologias digitais. Esse período 


\section{Tilusm Eltothato

ISSN: 1984-6444 | http://dx.doi.org/10.5902/1984644431227

também se destaca em razão das discussões para a implementação das DCNs, que entraram em vigor no início da década seguinte. Em meio aos avanços, nos anos 2000, muitos cursos de Relações Públicas foram criados no Brasil ${ }^{3}$. As discussões sobre o perfil do profissional continuaram no começo do novo milênio. Segundo o INEP/MEC (2017), 73 cursos de Relações Públicas estão em funcionamento, sendo 20 deles em instituições públicas e 53 em instituições privadas.

Uma alteração que pode mexer bastante com o ensino, mas que ainda não tem reais reflexos sobre a formação superior, é com relação às $\mathrm{DCNs}$ para a área de Relações Públicas, aprovadas em 2013, que estão apresentadas a seguir.

\section{As Diretrizes Curriculares Nacionais de Relações Públicas do Brasil de 2013}

Apesar de não fazer referência específica à emergência da cultura digital, o documento de 2013 que estabelece as DCNs de Relações Públicas menciona que o profissional deve ter domínio do processo comunicacional nas diversas mídias. Outra orientação do documento consta nos princípios gerais, quando se refere à questão da atualização dos cursos, responsabilizando-os pela oferta de condições, aos alunos, para que estes desenvolvam conhecimentos e práticas em mídias digitais, com recursos tecnológicos atualizados e constantes capacitações do corpo docente (BRASIL, 2013).

Em comparativo às antigas diretrizes, aprovadas em 2001 (BRASIL, 2002), que não eram específicas para a área de Relações Públicas, há três aspectos novos: a obrigatoriedade do estágio curricular, o aumento da carga horária mínima obrigatória do curso (de 2.700 para 3.200 horas) e a apresentação da estrutura, que, de conteúdos básicos e complementares, passou a ser descrita em eixos, com quatro aspectos previstos e estudo do cenário digital. Apesar de serem poucas qualitativamente, em termos de escopo, mexem muito com a estrutura atual dos cursos no país.

A implantação das diretrizes de 2013, em frente às anteriores, trouxe um tímido avanço com relação ao cenário digital. Entre outros fatores, a baixa participação das comunidades acadêmica e profissional no processo de discussão, tanto na consulta 


\section{Tusm Aillathá}

ISSN: 1984-6444 | http://dx.doi.org/10.5902/1984644431227

virtual quanto nas audiências públicas, provavelmente contribuiu para esse resultado. A estrutura que contempla os conteúdos curriculares do curso de Relações Públicas apresenta uma divisão em quatro eixos: Formação Geral; Comunicação; Relações Públicas; Formação Suplementar. No item 'Comunicação', o documento prevê estudos sobre o cenário digital em dois itens: a) estudos das mídias, das tecnologias de informação e de comunicação e b) estudos sobre cibercultura. Já no eixo 'Relações Públicas', há dois incisos voltados ao cenário digital, sendo: a) gerenciamento de crises, redação institucional, produção de mídias impressas, audiovisuais e digitais e b) comunicação em rede.

Em meio ao processo de transformações, é possível afirmar que as diretrizes atualizadas servem como linhas norteadoras gerais do que se espera do profissional de Relações Públicas no cenário digital e no que diz respeito às suas habilidades e competências comunicacionais, de modo que os estudantes não tenham uma formação desproporcional com relação às das demais áreas da comunicação. No Brasil, todos os cursos de Relações Públicas são de bacharelado. Já na Argentina, a situação é diferente, como veremos na sessão a seguir.

\section{As Relações Públicas na Argentina}

Segundo Ferrari (2004, p. 6), as Relações Públicas na Argentina surgiram ainda "na época das colônias, quando os primeiros 'lobistas', contra a tutela espanhola, foram os membros da primeira junta de governo de 1810". No entanto, a autora afirma que, oficialmente, o nascimento da função ocorreu apenas na metade do século XX:

Em 1930 já estavam instalados na Argentina o Banco de Galícia, Lever Brothers (atual Unilever), Shell, Siemens, Swift Armour, Banco Rio de la Plata, Ericsson, Colgate Palmolive, Astra, Bayer, Agfa-Gevaert, Price Waterhouse, Goodyear, Citibank, Kodak, Deloitte \& Touche, Dun \& Brandstreet, Esso, Ford, IBM, Duperial, Cyanamid e Banco de Boston. (FERRARI, 2004, p. 6).

No entanto, até o início dos anos 1960, o cargo de Relações Públicas era geralmente exercido por jornalistas, já que não existia educação acadêmica formal nesse campo. 


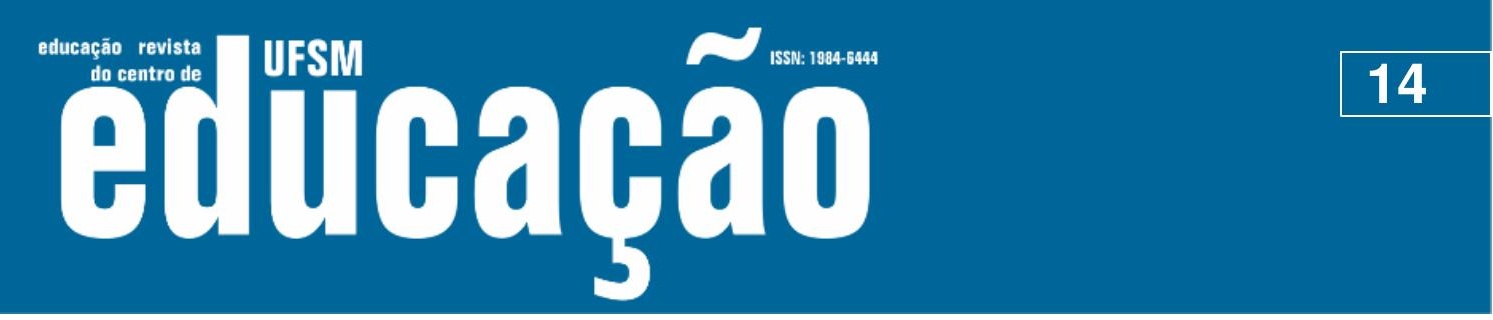

ISSN: 1984-6444 | http://dx.doi.org/10.5902/1984644431227

governo, enquanto outras, não. Estas últimas, da qual fazem parte as Relações Públicas, portanto, não contam com conteúdos mínimos. Por isso, as ementas dos cursos dessa área dependem de cada universidade.

Já quanto à nomenclatura, os cursos de graduação são denominados de: licenciatura em relações públicas ou, então, institucionais. Já nos cursos técnicos (pregrado), o predomínio de nomenclatura é para analista de relações públicas.

$\mathrm{Na}$ próxima seção, damos sequência ao estudo apresentando os detalhes sobre a formação de ensino superior uruguaia voltada à área de Relações Públicas.

\section{As Relações Públicas no Uruguai}

As atividades de Relações Públicas, no Uruguai, surgiram de maneira formal, no setor governamental, nos anos 1950, com a criação de um departamento especializado dentro das Forças Armadas. Na década de 1960, a empresa estatal ANCAP (Administração Nacional de Combustíveis, Álcool e Portland) foi pioneira, ao estabelecer um departamento de Relações Públicas.

No Uruguai, as entidades da categoria também tiveram um papel decisivo no desenvolvimento da área de Relações Públicas. "Quem incentivou a criação da Asociación Uruguaya de Relaciones Públicas (AURP) foi Radeck Balcárcel, então gerente de Relações Públicas da ANCAP e subsecretário do jornal El País" (FERRARI, 2004, p. 13). A associação, constituída em 19 de setembro de 1962, destaca, em seu estatuto, três objetivos principais:

a) conseguir que as relações públicas sejam desenvolvidas, consolidadas e divulgadas na República Oriental do Uruguai, com o caráter de especialidade orientada para o bem público e para uma convivência harmônica com todos os setores da sociedade; b) promover o intercâmbio de conhecimentos, técnicas entre os sócios, assim como entre as entidades do país e do exterior; c) defender a atividade de relações públicas, elevando-a a categoria de profissão no país. (FERRARI, 2004, p. 13).

A autora ainda ressalta a criação dos primeiros cursos da área no Uruguai:

Em 1966 começam os primeiros cursos de RP, patrocinados pela AURP. Os cursos foram ministrados pelo advogado e profissional de Relações Públicas argentino Dr. Carlos Panisello La Moglie. Juntamente, Román Perez Senac deu-se início ao curso de Relações Públicas Agrárias. Posteriormente foi criado o Instituto Uruguaio de Relações Públicas onde, por vários anos, foram 


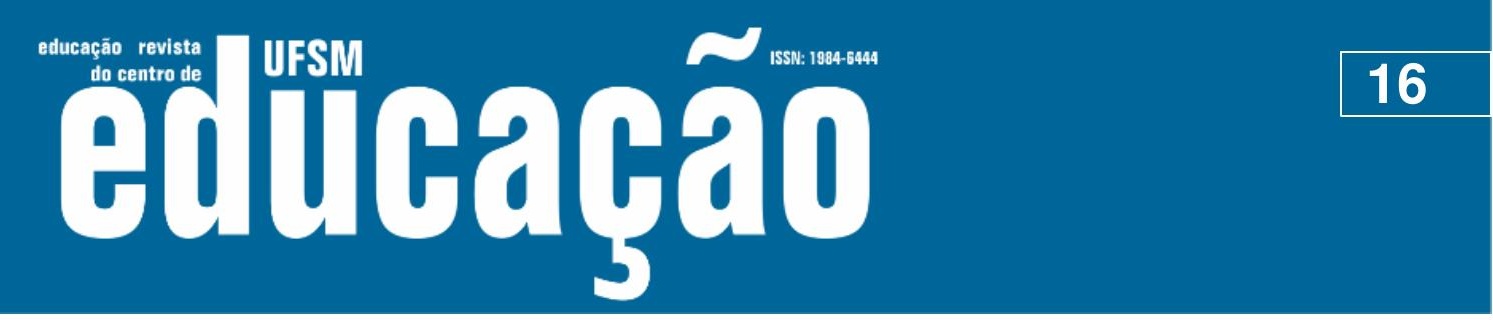

ISSN: 1984-6444 | http://dx.doi.org/10.5902/1984644431227

Relações Públicas, de dois anos, e Técnico de Relações Públicas e Gestão de Eventos, com duração de um ano.

A Universidad del Trabajo del Uruguay oferece formação de nível técnico e tem um curso de dois anos, concedendo o título de técnico em comunicação social. Quanto aos Institutos Técnicos, estes oferecem cursos geralmente com um ano de duração.

\section{Diretrizes curriculares de Relações Públicas no Uruguai}

No Uruguai, o Decreto no 104/14 (URUGUAI, 2014) dá concessão do reconhecimento às universidades e aos institutos sobre os diferentes cursos oferecidos, só levando em conta a carga horária, sendo a mínima de 2.200 horas. Sobre diretrizes curriculares ou conteúdo, não há uma orientação do Ministério de Educação uruguaio, ou seja, cada instituição tem autonomia a respeito dos cursos que oferece.

Segundo o presidente da AURP, Juan Pablo Topalian ${ }^{7}$, há, no país:

[...] um registro profissional. Mesmo tendo em conta os dados de membros de nossa organização, envolvidos em cursos de atualização profissional e seminários e o número de graduados universitários, atrevo-me a estimar que deve haver mais de mil profissionais que a exercem em nosso país. (TOPALIAN, 2015).

A requisição de título para exercer a profissão no país é bastante recente, já que os cursos superiores e técnicos oficiais não têm mais de 15 anos. Atualmente, é comum a exigência da formação em um desses cursos para a busca por vagas no mundo do trabalho. A AURP está trabalhando no desenvolvimento de uma legislação para as Relações Públicas e de um registro profissional, porém, ainda não há data para promulgação.

\section{Breve análise comparativa entre as diretrizes e orientações dos três países}

Conforme destacado nesta pesquisa, no Brasil, as DCNs para as Relações Públicas foram publicadas em 2013. Na Argentina e no Uruguai, não há documentos específicos para a área, apenas uma legislação ampla relacionada às orientações para o ensino superior. Nos dois países, os cursos e as instituições têm autonomia em relação aos conteúdos programáticos. 


\section{Us:

ISSN: 1984-6444 | http://dx.doi.org/10.5902/1984644431227

Nesse âmbito da discussão, se confirma a importância das Políticas de Educação Superior:

[...] as políticas de Educação Superior definem os territórios, as práticas e os signos acadêmicos, reconhecidos pelo Estado e pela sociedade; deverão sempre ter como referência a missão pública da Educação Superior para a formação política dos cidadãos, a Cultura, a Ciência \& Tecnologia, o desenvolvimento sustentável, a soberania nacional e a justiça social, assim como a crescente demanda popular pelo direito à Educação, inclusive Superior. (FRANCO; BITTAR, 2006, p. 166).

Em vista disso e com base no conteúdo até aqui exposto, o Quadro 1 traz uma síntese comparativa entre os três países, apontando as principais diferenças em relação ao ensino superior de Relações Públicas no cenário atual, especificamente no que concerne ao desenvolvimento digital. Na sequência do comparativo, segue uma explicação mais detalhada sobre os pontos apresentados no quadro.

Quadro 1 - Comparativo das Orientações/Diretrizes Curriculares de Relações Públicas entre Brasil, Argentina e Uruguai

\begin{tabular}{|c|c|c|c|}
\hline $\begin{array}{c}\text { ASPECTOS } \\
\text { ANALISADOS }\end{array}$ & BRASIL & ARGENTINA & URUGUAI \\
\hline $\begin{array}{l}\text { Perfil de Relações } \\
\text { Públicas }\end{array}$ & $\begin{array}{c}\text { Uma referência } \\
\text { (Art. 4으es. no 2/2013) }\end{array}$ & Não tem & Não tem \\
\hline $\begin{array}{l}\text { Competências } \\
\text { específicas para o } \\
\text { cenário digital }\end{array}$ & $\begin{array}{c}\text { Duas referências } \\
\text { (Eixo Formação em } \\
\text { Relações } \\
\text { Públicas/Res. no } \\
\text { 2/2013) }\end{array}$ & Não tem & Não tem \\
\hline $\begin{array}{l}\text { Carga horária mínima } \\
\text { do curso }\end{array}$ & 3.200 horas & 2.600 horas & 2.200 horas \\
\hline Estágio & Obrigatório & Não obrigatório & Não obrigatório \\
\hline Estrutura & $\begin{array}{l}\text { Quatro eixos: } \\
\text { (1) Formação geral; } \\
\text { (2) Formação em } \\
\text { Comunicação; } \\
\text { (3) Formação em } \\
\text { Relações Públicas; } \\
\text { (4) Formação } \\
\text { suplementar. }\end{array}$ & $\begin{array}{l}\text { As instituições de } \\
\text { ensino/cursos têm } \\
\text { autonomia para criar } \\
\text { os conteúdos. }\end{array}$ & $\begin{array}{l}\text { Os cursos têm } \\
\text { autonomia, não } \\
\text { havendo diretriz } \\
\text { que oriente os } \\
\text { conteúdos. }\end{array}$ \\
\hline
\end{tabular}

Fonte: Os autores.

Em relação ao perfil do egresso, observa-se, nas diretrizes brasileiras, a seguinte disposição: 


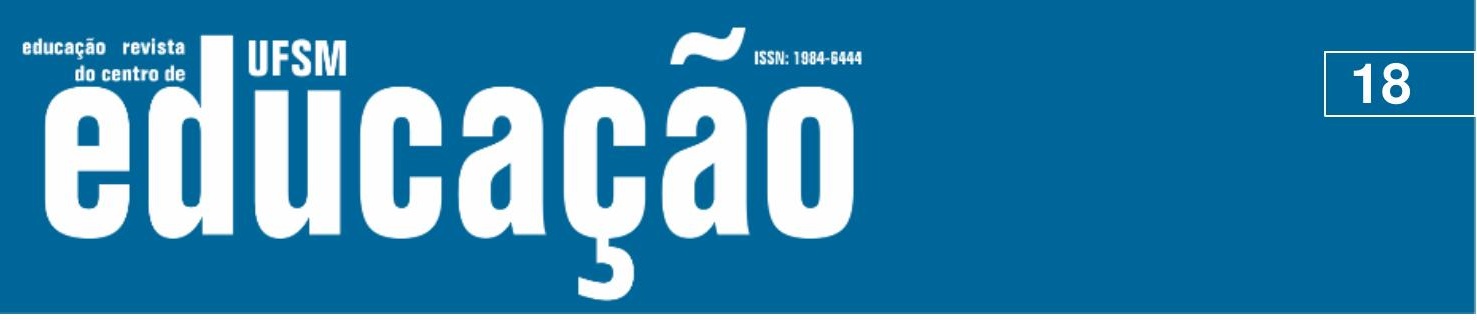

ISSN: 1984-6444 | http://dx.doi.org/10.5902/1984644431227

\begin{abstract}
O egresso do curso de Relações Públicas deve ser profissional ético, humanista, crítico e reflexivo, com as seguintes características pessoais: I capacidade acurada de análise conjuntural, de forma que se lide quantitativa e qualitativamente com dados estatísticos, econômicos e sociais, transformando-os em indicadores para a elaboração de políticas de comunicação; II - percepção das dinâmicas socioculturais, tendo em vista interpretar as demandas dos diversos tipos de organizações e dos públicos; III - compreensão das problemáticas contemporâneas, decorrentes da globalização, das tecnologias de informação ${ }^{8}$ e da comunicação e do desenvolvimento sustentável necessária ao planejamento de relações públicas; IV - entendimento do campo técnico-científico da comunicação, capaz de estabelecer visão sistêmica das políticas e estratégias de relacionamentos públicos; $\mathrm{V}$ - capacidade de liderança, negociação, tomada de decisão e visão empreendedora. (BRASIL, 2013).
\end{abstract}

Como não há diretrizes na Argentina e no Uruguai, não há descrição do perfil do egresso para os dois países.

Já com relação às competências do egresso em frente ao cenário digital, como mencionado anteriormente, nas diretrizes brasileiras, constam duas referências no eixo de Relações Públicas - gerenciamento de crises, redação institucional, produção de mídias impressas, audiovisuais e digitais e comunicação em rede. Já na Argentina e no Uruguai, não foi encontrada descrição para esse quesito.

Com respeito ao período de estudos, no Brasil, a carga mínima foi aumentada em 500 horas, a partir das diretrizes de 2013, passando de 2.700 para 3.200. $\mathrm{Na}$ Argentina são, no mínimo, 2.600 horas. No Uruguai, a carga mínima para cursos de graduação é de 2.200 horas.

Quando se trata do estágio, esta prática é obrigatória apenas no Brasil, tendo sido incorporada na mais recente atualização das DCNs. Nos outros dois países analisados, a obrigatoriedade dessa atividade não consta como integrante dos elementos de formação.

Com relação à estrutura, como já informado na seção descritiva do Brasil, o país conta com quatro eixos específicos de formação. Já na Argentina e no Uruguai, a ementa ainda é flexível, havendo mais autonomia na organização curricular, mas, no entanto, sem diretrizes que orientem os estudos em Relações Públicas.

Por fim, ainda é interessante considerar sobre a terminologia da área, questão abordada anteriormente nesta pesquisa. No Brasil, apesar de haver algumas exceções, em sua maioria, a formação é denominada como Relações Públicas, 


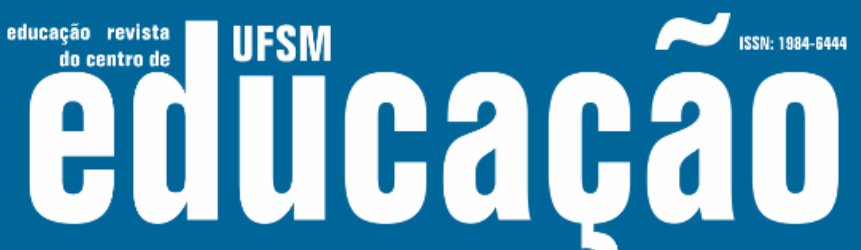

ISSN: 1984-6444 | http://dx.doi.org/10.5902/1984644431227

justificada por sua regulamentação, em 1967. Já na Argentina e Uruguai, aparecem outras nomenclaturas, conforme apresentado nas sessões descritivas dos dois países.

No cenário digital, cabe ao profissional de Relações Públicas estabelecer uma política eficaz de relacionamentos entre a organização e os seus públicos de interesse. Ademais, qualquer política de comunicação deve também inserir o contexto digital em todos os seus processos, desde o planejamento até a mensuração de ações, tendo-se em vista, principalmente, que há diversas ferramentas disponíveis para o detalhamento dos resultados alcançados.

\section{Considerações finais}

A tecnologia digital traz muitas facilidades, mas, também, representa um desafio para os cursos de graduação - em especial na área de Relações Públicas, tema desta discussão. Nesse cenário, é importante ressaltar que a sociedade passa por muitas transformações, as quais nem sempre acompanhadas pelas instituições de ensino superior. Em seu estudo, Terra (2006, p. 66) descreveu o "nascimento da comunicação organizacional digital e das relações públicas digitais, ambas decorrentes do fenômeno da digitalização e da evolução da sociedade". Ou seja, há ao menos uma década, o cenário digital faz parte de forma incisiva no trabalho de Relações Públicas e vem sendo encarado como objeto de estudo.

Nesse ínterim, como reforça Castells (2003, p. 212), o sistema educacional, como um todo, no mundo, "é, por tudo que se sabe, lamentavelmente inadequado para o uso dessa nova metodologia de aprendizado [...] Carece de professores capazes de usá-la com eficiência, além de pedagogia e organização institucional para estimular novas habilidades de aprendizado".

O ensino superior é o que prepara ou deveria preparar o profissional para o mundo do trabalho. Um estudo descrito por Gobbi (2010) mostrou um panorama da atuação dos graduados em Comunicação (não mostra de Relações Públicas especificamente, mas serve como um parâmetro). "97,4\% dos graduados em Comunicação Social do país atuam no mundo do trabalho, fora da 


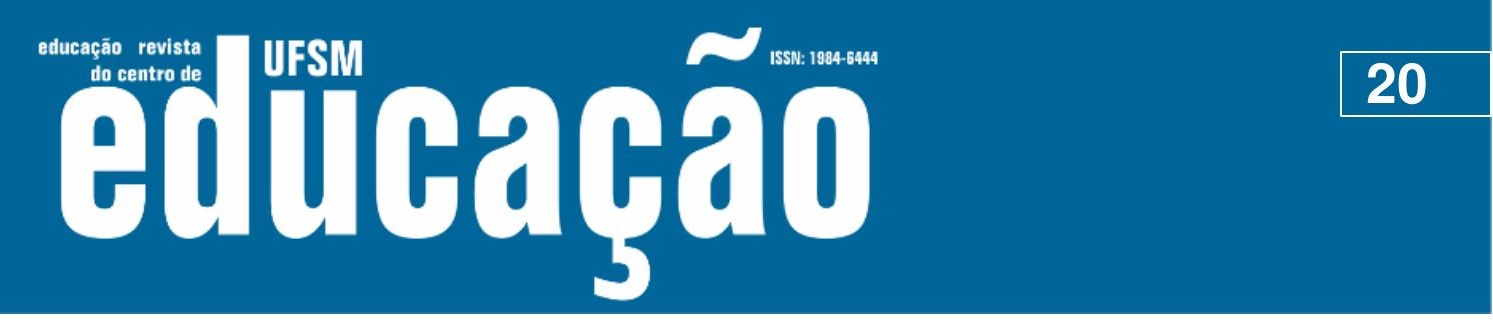

ISSN: 1984-6444 | http://dx.doi.org/10.5902/1984644431227

pesquisa/ensino/docência, de acordo com a pesquisa." (RHODEN, 2013, p. 20). Portanto, o que se reflete nesta pesquisa, ao comparar a realidade brasileira com a de outros países regionalmente próximos, é a questão de que o ensino superior de Relações Públicas tem de incorporar mais substancialmente a área no âmbito digital, de modo que esta seja uma perspectiva de atuação e ampliação para a vida profissional. No entanto, temos presenciado que:

\begin{abstract}
La universidad enfrenta un dilema importante en relación a la conjugación de sus propósitos estrictamente académicos, con los requerimientos de la sociedad, ya que a pesar de las muchas presiones, asociadas a la pertinencia social de su quehacer, conforme las características del contexto y de su tiempo, de estar al servicio de su entorno social, político y económico, de mejor posicionar a sus egresados en el mundo profesional, no puede convertirse tan solo en un instrumento a favor de la economía y de la demanda del mercado. El conocimiento que genera la investigación y la formación de profesionales es consubstancial a su existencia y por tanto, la universidad debe profundizar en lo que le es constitutivo. (CARRASCO, 2013, p. 46).
\end{abstract}

Corroborando essa visão, em termos de diretrizes, observou-se, na elaboração deste artigo, que, dentre os três países analisados, apenas o Brasil possui documentação específica para a área de Relações Públicas, e isso apenas desde 2013. Antes, a área integrava as orientações mais amplas para o campo da comunicação como todo. Além disso, a presença do cenário digital é pouco descrita, indo na contramão das atuais mudanças no mundo do trabalho. Na área de Relações Públicas isso representa funções na gestão das redes sociais e na inclusão de todas as ferramentas digitais num processo de comunicação.

Em vista dos dados expostos, entende-se que as DCNs podem ser implantadas de modo vanguardista, considerando as necessidades locais e regionais nos PPCs, com mais referências ao cenário digital. Isso envolve um sistema que integre o que se espera do profissional da área, o perfil do egresso, suas competências e habilidades, em consonância com uma legislação pertinente e oportunidades profissionais.

No Brasil, apesar de já haver documentação, percebem-se lacunas, tanto de estrutura curricular quanto de participação das instituições interessadas, especialmente em meio ao cenário multimídia que envolve nossa sociedade. Nos países vizinhos aqui analisados, Argentina e Uruguai, um dos principais fatores que 


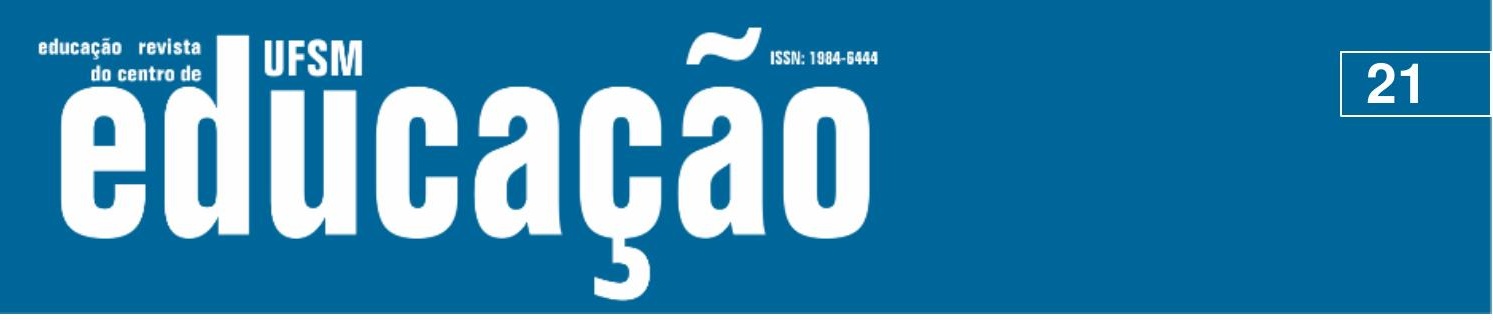

ISSN: 1984-6444 | http://dx.doi.org/10.5902/1984644431227

ainda necessita de avanços é a própria estruturação de um documento norteador, o que reforça a necessidade de ampliar as discussões a respeito do mundo do trabalho de Relações Públicas em frente à era digital.

\section{Referências}

ARGENTINA. Ministério de Cultura e Educação. Lei de Educação Superior, no 24.521, de 20 de julho de 1995. Disponível em: http://secgral.unsl.edu.ar/docs/Ley\%2024521\%20de\%20Educacion\%20Superior.pdf. Acesso em: 20 nov. 2017.

ARGENTINA. Ministério de Cultura e Educação. Resolução nº 6, 13 de fevereiro de 1997.

Disponível

em: http://informacionpresupuestaria.siu.edu.ar/DocumentosSPU/dngu/RM_6-97.pdf. Acesso em: 4 nov. 2017.

BAUMAN, Zygmunt. Turistas e vagabundos. In: BAUMAN, Zygmunt. Globalização: as consequências humanas. Rio de Janeiro: Jorge Zahar, 1999. p. 85-110.

BARICHELLO, Eugênia Maria Mariano da Rocha. Ensino das profissões midiáticas: trajetória do curso de comunicação da UFSM. In: MOURA, Cláudia Peixoto de (Org.). História das relações públicas: fragmentos da memória de uma área. Porto Alegre: EDIPUCRS, 2008. p. 536-551.

BARICHELLO, Eugênia Maria Mariano da Rocha. Apontamentos sobre as estratégias de comunicação mediadas por computador nas organizações contemporâneas. In: KUNSCH, M. M. K. (Org.). Comunicação organizacional: histórico, fundamentos e processos. v. 1. São Paulo: Saraiva, 2009. p. 337-353.

BORTOLAZZO, Sandro Faccin. O imperativo da cultura digital: entre novas tecnologias e estudos culturais. Revista Cadernos de Comunicação, UFSM, Santa Maria, v.20, jan/abr.2016.

BRASIL. Lei n. 5.377, de 11 de dezembro de 1967. Disciplina a Profissão de Relações Públicas e dá outras providências. Diário Oficial da União, Poder Executivo, Brasília, DF, 12 dez. 1967. Seção 1, p. 12477. Disponível em: http://www.planalto.gov.br/ccivil_03/leis/1950-1969/L5377.htm. Acesso em: 12 dez. 2017.

BRASIL. Conselho Nacional de Educação. Câmara de Educação Superior. Parecer no 776, aprovado em 3 de dezembro de 1997. Orientação para as diretrizes curriculares dos cursos de graduação. Disponível em: http://portal.mec.gov.br/cne/arquivos/pdf/CES0776.pdf. Acesso em: 27 jan. 2018. 


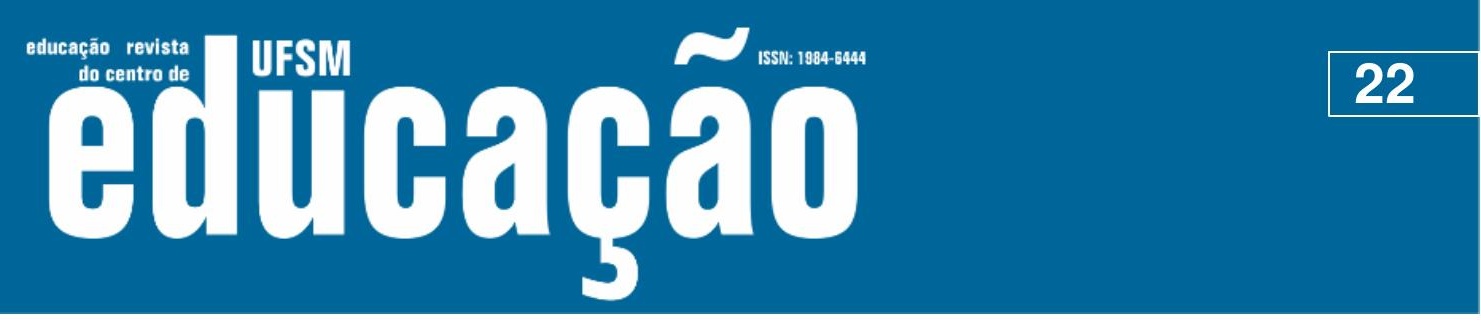

ISSN: 1984-6444 | http://dx.doi.org/10.5902/1984644431227

BRASIL. Ministério da Educação. Parecer CNE/CES nำ1.363, de 12 de dezembro de 2001. Retifica o Parecer CNE/CES no 492/2001, de 4 de julho de 2001, publicado no Diário Oficial da União de 9 de julho de 2001, seção 1E, página 50, favorável à aprovação dos Projetos de Resolução que instituem as Diretrizes Curriculares Nacionais dos cursos de Filosofia, História, Geografia, Serviço Social, Comunicação Social, Ciências Sociais, Letras, Biblioteconomia, Arquivologia e Museologia. Diário Oficial da União, Poder Executivo, Brasília, DF, 29 jan. 2002. Seção 1, p. 60. Disponível em: http://pesquisa.in.gov.br/imprensa/jsp/visualiza/index.jsp?jornal=1\&pagina $=60 \&$ data $=$ 29/01/2002. Acesso em: 2 out. 2017.

BRASIL. Ministério da Educação. Resolução nํㅜ 2, de 27 de setembro de 2013. Institui as Diretrizes Curriculares Nacionais do curso de graduação em Relações Públicas. Diário Oficial da União, Poder Executivo, Brasília, DF, 1 out. 2013. Seção 1, p. 2829. Disponível em: http://pesquisa.in.gov.br/imprensa/jsp/visualiza/index.jsp?data=01/10/2013\&jornal=1 \&pagina=28\&totalArquivos=96 . Acesso em: 2 out. 2017.

CAMPANELLA, Lana D'ávila. Estudo da bibliografia na disciplina: "teorias de relações públicas" dos cursos de relações públicas brasileiros: uma análise das obras básicas utilizadas na disciplina. 2008. 303 f. Tese (doutorado em comunicação)Pontifícia Universidade Católica do Rio Grande Do Sul, Porto Alegre, 2008.

CASTELLS, Manuel. A galáxia da internet: reflexões sobre a internet, os negócios e a sociedade. Tradução Maria Luiza Borges. Rio de Janeiro: Zahar, 2003.

CASTELLS, Manuel. Creatividad, innovación y cultura digital: un mapa de sus interacciones. Revista Telos, n. 77, oct./dic. 2008. Disponível em: https://telos.fundaciontelefonica.com/\%20telos/articulocuaderno.asp@idarticulo=2\&r ev=77.htm. Acesso em: 9 fev. 2018.

CARRASCO, María Zuñiga. Innovación en educación superior. In: SÁNCHEZ, Aurélio Vila (Ed.) Las universidades como generadoras de la innovación: investigación, iniciativa y responsabilidad social. Costa Rica: Foro Internacional sobre Innovación Universitaria, 2013. p. 35-60.

CUNHA, Maria Isabel; ISAIA, Silvia Maria de Aguiar. Professor da educação superior. In: MOROSINI, Marília Costa (Ed.). Enciclopédia de Pedagogia Universitária: glossário. v. 2. Brasília: INEP, 2006. p. 349-406.

FRANCO, Maria Estela Dal Pai; BITTAR, Mariluce. Políticas públicas da educação superior. In: MOROSINI, Marília Costa (Ed.). Enciclopédia de pedagogia universitária: glossário. v. 2. Brasília: INEP, 2006. p.163-209. 


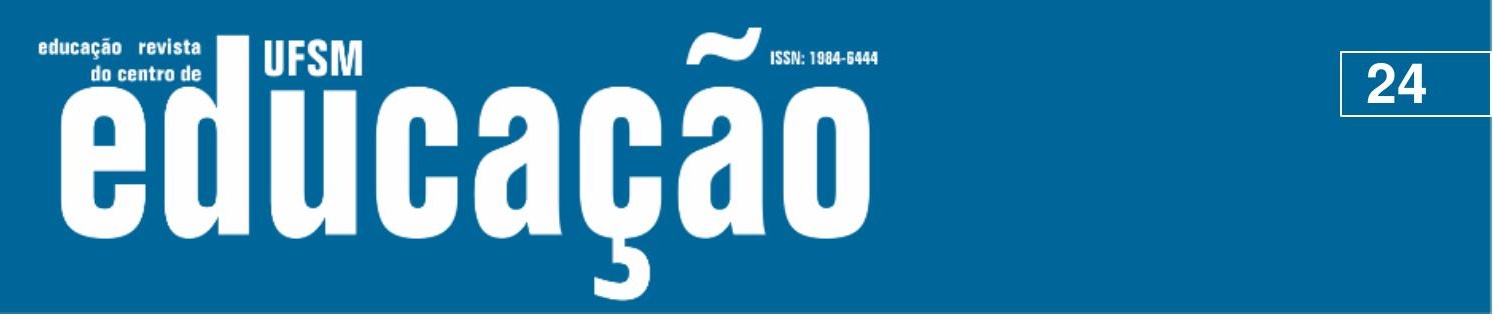

ISSN: 1984-6444 | http://dx.doi.org/10.5902/1984644431227

NEGROPONTE, Nicholas. A vida digital. Tradução Sérgio Tellaroli. São Paulo: Companhia das Letras, 1995.

OLIVEIRA, Valeska Maria Fortes de. O professor universitário: saberes acadêmicos e demandas profissionais. In: MOROSINI, Marília Costa (Org.) Enciclopédia de pedagogia universitária. Porto Alegre: FAPERGS/RIES, 2003. p. 253-261.

RHODEN, Valmor. O ensino superior de relações públicas: formação digital, práticas e desafios na UFSM. 2013. 331 f. Tese (Doutorado em Comunicação Social) - Programa de Pós-Graduação em Comunicação Social, Faculdade de Comunicação Social, Pontifícia Universidade Católica do Rio Grande do Sul, Porto Alegre, 2013.

TEIXEIRA, João Evangelista. Relações públicas na Umesp: 30 anos de História. São Bernardo do Campo: UMESP, 2002.

TERRA, Caroline Frazon. Digital: o futuro das relações públicas na rede. 2006. 173 p. Dissertação (Mestrado em Ciências da Comunicação). Universidade de São Paulo, São Paulo, 2006.

TOPALIAN, Juan Pablo. Asociación Uruguaya de Relaciones Públicas [mensagem pessoal]. Mensagem recebida por vrhoden6@gmail.com, em 13 set. 2015.

URUGUAI. Ministério de Educação e Cultura. Decreto no 104/14. Disponível em: http://educacion.mec.gub.uy/innovaportal/file/54856/1/decreto_104-014.pdf. Acesso em: 4 out. 2017.

\section{Correspondência}

Valmor Rhoden - Universidade Federal do Pampa - Rua Ver. Alberto Benevenuto, 3200 Passo, CEP 97670000, São Borja, Rio Grande do Sul, Brasil.

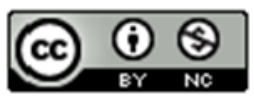

This work is licensed under a Creative Commons Attribution-NonCommercial 4.0 International (CC BY-NC 4.0)

\section{Notas}

\footnotetext{
${ }^{1}$ Há duas nomenclaturas possíveis: Relações-Públicas, com hífen, e Relações Públicas, sem hífen. A primeira designa o profissional e a segunda, a atividade. Fonte: Portaria $\mathrm{n}^{\mathrm{o}} 116$, de 09 de maio de 2011 , do Conferp. Disponível em: http://www.conferp.org.br/?p=2728. Acesso em: 12 mai. 2017.

${ }^{2}$ Disponível em: http://g1.globo.com/tecnologia/noticia/2015/05/mundo-tem-32-bilhoes-de-pessoas-conectadasinternet-diz-uit.html. Acesso em: 19 fev. 2018.

${ }^{3}$ Dados do Inep/MEC apontavam que, em julho de 2009, havia 127 cursos presenciais credenciados no país.
} 


\section{Lusm \\ ISSN: 1984-6444

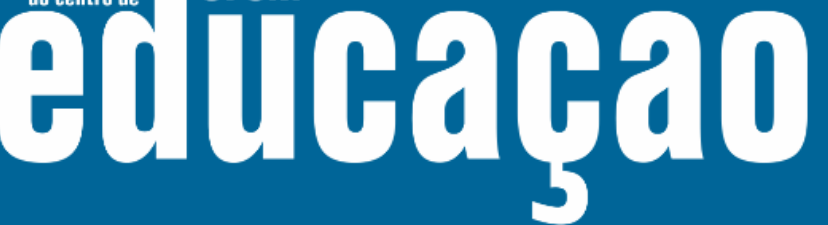

ISSN: 1984-6444 | http://dx.doi.org/10.5902/1984644431227

${ }^{4}$ Dados do Ministerio de Educación y Deportes de Argentina. Disponível em: http://titulosoficiales.siu.edu.ar. Acesso em: 31 jul. 2017.

${ }^{5}$ Significa gestor neste contexto.

${ }^{6}$ Não Relações Públicas especificamente.

${ }^{7}$ Trecho retirado de mensagem eletrônica enviada, conforme referência constante na lista ao fim deste artigo.

${ }^{8}$ Grifo nosso. 